\title{
USING OPEN PROBLEMS AND COOPERATIVE METHODS IN MATHEMATICS EDUCATION
}

\author{
András Ambrus \\ Eötvös Loránd University, Budapest•ambrus@cs.elte.hu \\ Krisztina Barczi-Veres \\ Eötvös Loránd University, Budapest
}

\begin{abstract}
Mathematics education is very country specific. Roughly speaking we can differentiate between two main styles in teaching mathematics: either the focus is on the students or the focus is on mathematics as a science. Hungarian mathematics teaching belongs to the second style. What can a teacher do in such tradition, are there chances to change the traditional boundaries? In our article we report about a teaching experience concentrating on the role of the teacher when changing the one-sided classroom teaching and also presenting students' points of view in the changed teaching environment. Two aspects are taken into consideration in connection with mathematical problem solving: open problems and cooperative teaching.
\end{abstract}

\section{Introduction}

After visiting some mathematics lessons in Hungarian schools, Laurinda Brown from Bristol University formulated her opinion: "You, in Hungary are teaching mathematics, we in England children!" Jose Carillo from Huelva University said: "You, in Hungary teach much more mathematics and on higher level than we in Spain." At first sight these statements are promising and nice but if we look behind the nice picture we notice huge problems, too. The results of some national and international tests indicate that although the mathematical content of the Hungarian mathematics education is at a rather high level, our students are not good enough when it comes to using mathematical competencies. Let us have a look at some of these tests:

\section{PISA test}

On PISA 2014 Mathematics test out of the 65 participants Hungary reached the $39^{\text {th }}$ place with an average of 477 points (OECD average is 494 points). The top rating level 6 was reached only by $9.3 \%$ of the Hungarian students, the lower levels 2 or 1 were achieved by 28.1\%. On the creative problem solving PISA 2012 test out of the 44 participants Hungary placed $33^{\text {rd }}$. Here, $35 \%$ of the Hungarian students reached level 2 or level 1 . Hungary has always participated in PISA tests right from the beginning, usually achieving OECD average results, but these results show a decreasing tendency.

\section{Matura exam}

In Hungarian mathematics education it is the central exam at the end of year 12 which has two levels, middle and higher level. Most of the higher-level problems are complex problems; many of them are modelling problems while the middle level problems usually 
include basic mathematical tasks, algorithms or procedures. In a year about 95000 students take the mathematics matura exam out of whom about 3500 students take the higher level exam. (3.6\%!) Universities training engineers, information technologists, mathematicians, mathematics teachers, architects have places to offer for about 20-25\% of a year group but only about $3.6 \%$ of a year group takes the higher level maturity exam in mathematics, although a high level of mathematical knowledge is a requirement for these majors.

\section{University tests for first year students}

First year students have to sit a test at the beginning of their university or college studies in which the problems are based on the middle level maturity exam requirements. Based on their result most of the students must participate on an "adjustment" course where they go through the basic secondary mathematical concepts, algorithms, procedures, et cetera.

To summarize: it seems that the whole system - the Hungarian elementary and secondary mathematics education does not work very effectively. But what can we do to achieve some changes in the current education system? In this article we concentrate only on one but an important issue: How can we reach not only the top $10 \%$ of students in mathematics lessons but also "the rest", the less able ones? Our hypothesis is that the teaching style of mathematics that works for the top ten percent is not effective for the next 10-20\%. In a conversation J. Mason said: "The much-vaunted Hungarian mathematics teaching has not spread significantly into the mainstream." Maybe one of the reasons for this is that the abstract style might be suitable for the talented but unfitting for the less talented and the average students. What we are interested in is how we can reach more students to help them become better problem-solvers in mathematics. In this article we concentrate on opening closed problems, which are typical in Hungarian mathematics teaching and on applying cooperative teaching methods, which are rarely used in Hungarian secondary school mathematics teaching. We report about a secondary school experiment based on which the teacher compares the traditional class teaching to teaching using cooperative techniques.

\section{Theoretical background}

We mentioned above that frontal teaching is dominant in Hungarian mathematics education and there is a tradition - maybe thanks to G. Pólya - that the so-called problemoriented style is used frequently, however the efficacy of this style is not obvious. On one hand in a frontal classroom it is the brightest students who understand the problems or questions and they are the ones who usually react to the teacher's questions. Furthermore, those who do not understand the lesson often become frustrated; therefore, they stop taking part or simply just copy the brighter ones. On the other hand, frontal work has many advantages. For example, in frontal work less time is needed to teach the same content and 
make students practice it as well than when using cooperative work or minimally guided projects or problem solving (Clark, 2012).

To support these views I can quote two of my students who I tutor: K.V., a year 11 student said previously: "In year 9 I already lost track of what is going on in mathematics lessons." O.V., a year 7 student answered my question "What did you learn in today's mathematics lesson at school?" earlier with "I do not know." In her exercise book I saw some unclean figures without any sensible statements.

Inevitably, there is a huge difference between novices and experts in problem solving. In the following section we analyse the reasons. We concentrate on some findings of cognitive neuroscience to demonstrate how different the students can be when it comes to learning mathematics and which factors should be taken into consideration in mathematics teaching. Our basic view is: effective mathematics teaching does not exist without taking the human cognitive architecture into consideration. Unfortunately, the pedagogical and psychological sciences are neglected in the Hungarian mathematics education instead of these the science mathematics plays a one-sided dominant role.

\subsection{Memory structures}

Most neuroscientists accept Baddeley's (2009) model of memory structures in which working memory and long term memory play a vital role. In this section we analyse these components of the memory systems in detail.

\section{Working memory (WM)}

In problem solving, the role of $W M$ is vital. It is called the workbench of our brain; it is the active problem space. It has four components: phonological loop to hold and rehears verbal information; visual-spatial sketchpad to hold and rehears visual and spatial information; episodic buffer which connects the verbal and visual-spatial information directed by the central executive with the help of the information taken from the long term memory. The central executive is the so-called supervisory attention system, because it monitors and controls the information processing in our brain (Figure 1).

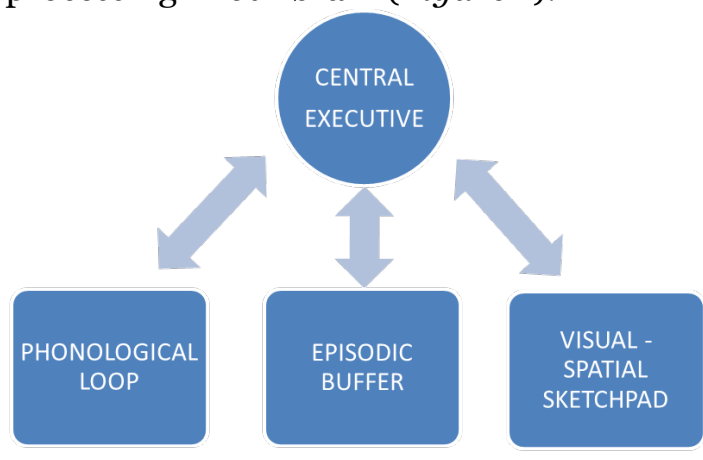

Figure 1 The Working Memory Model

Our $W M$ constructs plans, uses transformation strategies, analogies, metaphors, brings together things in thought, abstracts and externalizes mental representations. In problem solving students need a clear mental representation of the task (Understanding the 
problem). While seeking a strategy (solution method), students need to hold the conditions and the goal and the possible transformation (solution) steps in their memory, and taken this into consideration they should monitor their progress in the solution, inhibit wrong, unsuccessful ideas and check their results. These steps need too much resource from the $W M$, for novices it exceeds the whole capacity and they learn nothing. It is one reason why problem-oriented teaching does not work for average students. The $W M$ has a very limited capacity holding $7 \pm 2$ info units, its time limit is $18-30 \mathrm{sec}$ without rehearsal, goal maintenance and inhibition of irrelevant information.

\section{Long term memory (LTM)}

The LTM contains information in form of schemas. Schemas are abstract, structured, dynamic representations of information. Schema automaticity means a skill, procedure is learned so that it does not place demand on the $W M$ to deal with it. It has a very important consequence: we may extend the capacity of the $W M$ with recalling relevant schema from the $L T M$ it functions as only one information unit in the WM. (See capacity limit!) In the $W M$ novel information is incorporated into existing schema(s), or similar schema(s) are produced and altered or new schema(s) are recoded back into the LTM. A huge difference between experts and novices is that experts have a lot of solution schemas, which they can apply in traditional problem solving but novices do not have such schemas (Figure 2).

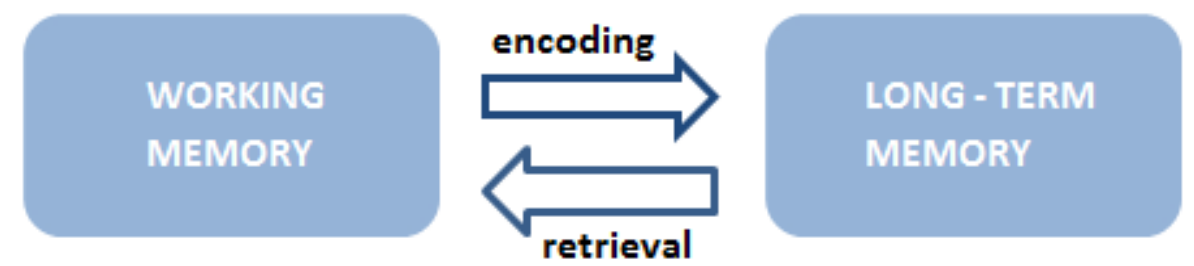

Figure 2 Working memory and long - term memory

\subsection{Overcoming the limits of working memory: Cognitive load theory}

Cognitive load can be defined as the load imposed on the $W M$ by information being presented. It is based on the following assumptions:

1. The capacity of the working memory is limited.

2. Pieces of information are stored as schemas in the long term memory.

3. Schemas represent units of information.

4. Automaticity of schemas in the long term memory can be achieved.

5. Learning requires active conscious process in the working memory.

\section{Intrinsic cognitive load}

Intrinsic cognitive load depends on the elements that must be processed simultaneously. For example when solving word problems: reading the problem, concluding what the problem asks, solving the problem are elements which interact. The intrinsic cognitive load 
is embedded in the problem, we as teachers cannot influence them. For example solving $5+6$ has low intrinsic cognitive load and solving $2 \frac{3}{4}+5 \frac{6}{7}$ has high intrinsic load.

\section{Extraneous cognitive load}

Extraneous cognitive load depends on the way the information is presented. May include superfluous information that is not necessary for learning the presented material such as background music or holding mental representations of facts or figures. For example, for some students it might be hard to understand that a geometrical figure and the corresponding statements are separated.

\section{Germane cognitive load}

Germane cognitive load means the cognitive load placed on the $W M$ at schema formation, integration and automation. It explains the differences between students in terms of experience, ability level and content knowledge.

The actual cognitive load imposed on the working memory is composed from the intrinsic load, the extraneous load and the germane load. The possible cognitive loads need to be taken into consideration when planning our teaching. For successful problem solving reduction of the cognitive load is an essential aspect which can be achieved by:

1. Applying goal free (open) problems. In case of some problems the distance between the starting phase and the goal is very big and students are asked to find as many pieces of data as they can. Example: "In a triangle two sides are 7 $\mathrm{cm}$ and $11 \mathrm{~cm}$ long, the angle between them is $73^{\circ}$. Find all the missing information about this triangle that you can.” In our experiment opening problems goes in this direction

2. Applying cooperative teaching methods as research experiments show that in group work the $W M$ capacities of the members are added together, so the cognitive load is not very high for the individuals (Clark, 2012). Our classroom experiment is based on group work.

\subsection{Cooperative teaching techniques}

Most people think that cooperative learning means simply arranging students in groups and give them a problem to solve. Although it is true that in cooperative learning the students are arranged in groups and their aim is to solve a problem or to achieve another previously set goal, but it is not their task to decide who does which part of the job, who takes the most responsibility and so forth. To avoid one student doing all the work while the others just listen or do not even take part the following four principles were introduced: positive interdependence, individual accountability, equal participation, and simultaneous interactions. These four principles ensure that every member of the group participates actively and takes responsibility for the task at hand. (Johnson \& Johnson, 1994) To assure that these four principles are present different structures were introduced which were given 
catchy names to make them easy to remember and refer to (Kagan, 2003). Here are some examples for cooperative structures:

- Think-Pair-Share (Kagan, 2001): Students work in groups of four. A problem is presented to the students then they are given time to think on their own about possible answers for a specific amount of time. Finally, students discuss their answers in twos.

- Round Robin (Kagan, 2004): This structure gives an opportunity for each member of the group to speak. Starting with one student, everyone gets 1- 3 minutes to present their point of view.

- Jigsaw (Slavin, 1995): Each team needs to become an expert of a topic/solution of a problem in a set time. After this new groups are formed with one member from each of the original groups and the members share their knowledge. Finally, everyone goes back to the original groups.

When talking about cooperative learning there are two important aspects of teaching that need to be considered. First, we need to think carefully about organizing students into groups. The grouping principles might depend on the teacher, the students, the subject, the type of the lesson ... etc. However, according to Burns (1990) the ideal group size is always four as in a group of four two pairs can easily be formed and no one is left out. The second issue is the role of the teacher. In a cooperative classroom the teacher is not to person who controls everything, but he becomes an observer or a coach. Obviously, the teacher is still needed for example for maintaining the right environment for learning and not to let the classroom turn into a chat room (Dees, 1990). Furthermore, it is the teacher's task to walk around the classroom and help the groups overcome the obstacles or give an instant feedback for the groups.

In Hungary cooperative teaching appeared in education as a result of József Benda's work He believed that this teaching method can contribute to the integration, achievement and development of students (Józsa \& Székely, 2004).

\subsection{Open problems, investigations}

Open problems can be investigations, real - life situations, projects or problem fields (Pehkonen, 1999). They can be created by problem posing, problem variations or by working with problem fields, as well. These types of problems allow students to work in their own pace, to find more solutions thus giving the opportunity to children with different mathematical abilities to feel successful (Way, 2013). Furthermore, open problems are effective means of teaching problem solving since students can experiment with the task at hand and can formulate new problems as they advance in their solution (Zimmermann, 1986).

The reason we chose to experiment with cooperative techniques and open problems apart from the test results mentioned above - is that in Hungarian classrooms we face the following problem more and more often: students are less independent when it comes to 
solving mathematical problems individually - based on discussions with teachers of other science subjects we can say that this tendency is unfortunately present not only in mathematics lessons. Many students are passive listeners when the teacher presents a new material, they try to follow the explanations or the solution of a sample problem but when they have to solve similar or totally different problems on their own the majority looks helpless. A lot of students find it challenging to see which idea leads to the solution, many have difficulties with communicating their ideas correctly, and checking their solutions or their way of thinking - which according to Pólya (1973) is a crucial step in problem solving - is usually completely missing from their work. Moreover, the ability to generalize certain statements and the need for proof needs to be developed in secondary school mathematics, as well.

\section{The experiment}

The experiment was designed in the form of an action research where the teacher of the class was the researcher as well. Action research is usually carried out by practising teachers who research their own practice for achieving professional development. This type of research is participatory and situation-based (Koshy, 2005). Furthermore it is an effective tool for bringing mathematics education and education-based research closer together (Zimmermann, 2009).

The school where the experiment took place is a highly selective secondary school taking the best achieving students from the region. It is a mixed comprehensive secondary school with students from 12 to 20 years old. The students who were chosen to participate in the experiment were 16 - 17 years old. After this group of sixteen students was selected they were offered to choose not to take part in the experiment, but none of them did so. Moreover, as the lessons were voice and video recorded, the parents were asked to sign consent to their children's participation. In the year of the experiment the students attended a class that specializes in maths and foreign languages. They were not necessary talented in mathematics but they were motivated and the majority of them had a great interest in mathematics and science subjects. In their first year, which was a preparatory year for them, they had three maths lesson a week then in the next two years they had four maths lessons a week. In the year of the experiment the class followed the year 10 scheme of work for Hungarian secondary schools.

The experiment consisted of two main parts: the first part included 12 consecutive lessons - in Hungary lessons are 45 minutes long - at the beginning of the year, the second one about 12 separate lesson throughout the school year. In the first part 5 mathematical problems were discussed whose topic was in line with what the students had learned in the previous years. Although these problems were curriculum based in terms of their mathematical content, the form they were presented in was unusual for the students. In Hungarian textbooks mathematical problems are mainly closed problems. However, the problems used in the first part of the experiment were either investigations or open 
problems or problems that could be opened. Each lesson was planned using cooperative teaching techniques. In the second part of the experiment we continued working with the year 10 scheme of work and one lesson every $2-3$ weeks, depending on the topic, was planned with cooperative techniques. The types of the lessons ranged from introducing a new material through practice to summarizing a certain topic. The problems discussed in this phase were based on the topic being covered and their type was mainly familiar for the students, however some of them were presented in the form of open problems or investigations.

Data was collected in several different ways. Firstly, each student had a so called "reflection booklet" which was an exercise books where students kept record of their mathematical problem solving activity and any other thoughts related to problem solving or cooperative work. Secondly, half of the lessons were video recorded and the majority of the group work was voice recorded. Moreover, before starting the experiment the students filled in a mathematical pre-test, which tested heuristic strategies and mathematical knowledge needed for the first five problems and various psychological questionnaires (Ambrus, 2004, Tóth, 2007). The first part of the experiment was followed by a mathematical post- test and at the end of the school year students repeated the psychological questionnaires, filled in a questionnaire related to cooperative learning (Mécs, 2009) and completed a mathematical delayed test. This latter was exactly the same as the post- test.

\section{Comparing a frontal and a cooperative lesson from the second part of the experiment}

\subsection{Frontal teaching - closed problems}

In Hungary the vast majority of mathematics lessons are planned using frontal teaching. When introducing a new material the teacher presents it to the class - of course there are lead-in exercises and usually there is a conversation between the teacher and the class which means that most of the students are passive rather than active participants in the teaching and learning process. In practice lessons the students are given a worksheet or a set of problems, which they have to work on and after a while the results and the solution methods are discussed with the whole class. For practising generalizing trigonometric ratios the following worksheet was used (the students had already learned how to interpret trigonometric ratios for angles bigger than $90^{\circ}$ and how to find angles if the trigonometric ratio was given):

Complete the following tasks. (Barczi, 2014)

1. Without using a protractor mark the following angles in the Cartesian coordinate grid:

a) $120^{\circ}$

b) $-45^{\circ}$

c) $-130^{\circ}$ 


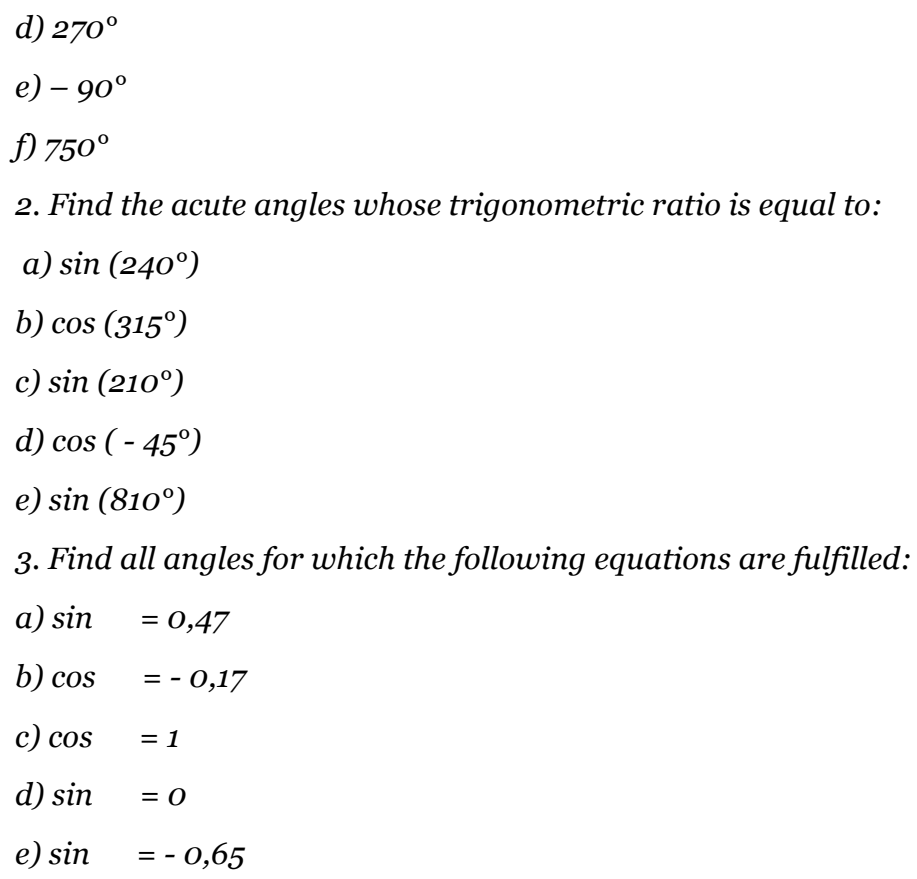

In the a lesson in which we used the worksheet above the students had to solve the problems individually, however they could choose to ask for help from or to give help to other students or they could ask for the teacher's assistance, too. The solutions were checked as we went along in the form of a whole class discussion. This teaching format allowed the less active or less confident students just to sit around and did not necessary help the development of understanding of every student.

\subsection{Cooperative methods - investigation}

As we were interested in the students' reaction to working in groups we planned a lesson with cooperative techniques whose topic was generalizing trigonometric ratios. The lesson was again a practice lesson. The problem we selected was an investigation which according to Pehkonen (1999) can be considered as an open problem. Based on the first part of the experiment we think that cooperative work provides a good opportunity to use open problems, investigations.

In the lesson students were working in groups of four (Figure 3) and they had to solve the following task.

\section{Group 1}

Given two segments $a=8 \mathrm{~cm}$ and $b=6 \mathrm{~cm}$ and the trigonometric ratio of an angle $\sin \alpha=0,8$. Are there any triangles whose sides are the segments and whose angle is the given angle? Try to find and draw all possible triangles.

\section{Group 2}

Given two segments $a=7 \mathrm{~cm}$ and $b=5 \mathrm{~cm}$ and the trigonometric ratio of an angle sin $\alpha=0,4$. Are there any triangles whose sides are the segments and whose angle is the given angle? Try to find and draw all possible triangles. 


\section{Group 3}

Given two segments $a=10 \mathrm{~cm}$ and $b=7 \mathrm{~cm}$ and the trigonometric ratio of an angle $\sin \alpha=0,2$. Are there any triangles whose sides are the segments and whose angle is the given angle? Try to find and draw all possible triangles.

Group 4

Given two segments $a=9 \mathrm{~cm}$ and $b=6 \mathrm{~cm}$ and the trigonometric ratio of an angle $\sin \alpha=0,2$. Are there any triangles whose sides are the segments and whose angle is the given angle? Try to find and draw all possible triangles.

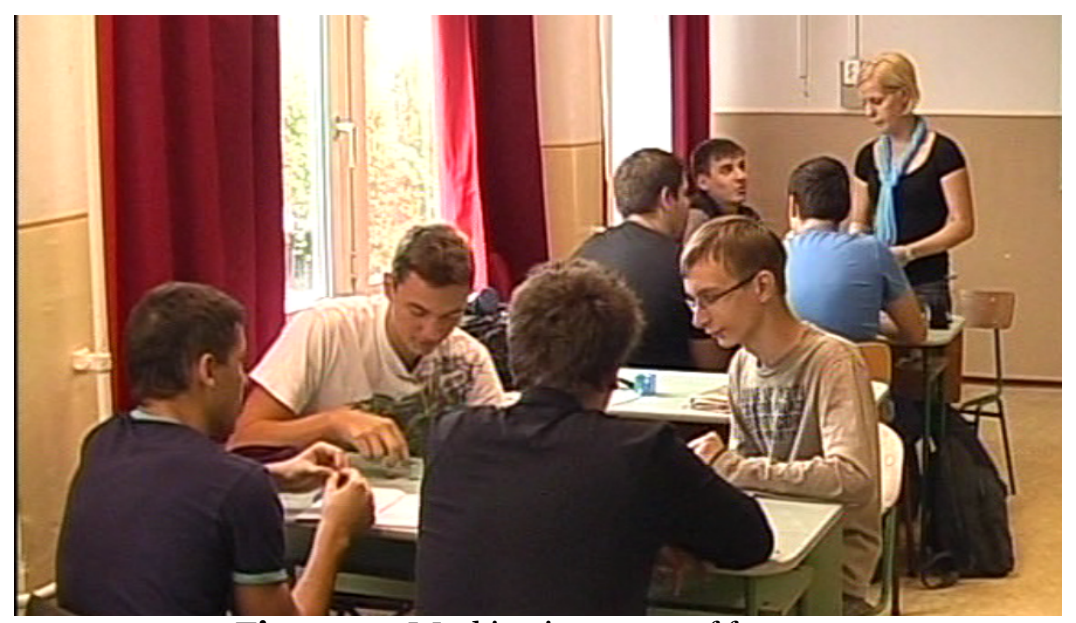

Figure 3 Working in groups of four

The lesson plan was the following (Barczi, 2014):

1. Forming groups

2. Trying to solve the task using the structures "Think-Pair-Share" and "Round Robin”

3. Group discussion in groups of four to make sure that every member understands the ideas and the group's solution

4. Sharing the different solutions of the groups using the structure "Jigsaw"

5. Collecting all the solutions and checking ideas through class discussion.

\section{Results}

\subsection{The students' perspective}

In this section we present a questionnaire (Mécs, 2009) that is related to cooperative work (Table 1). This questionnaire was filled in by the students at the end of the whole experiment.

To obtain more information about what students thought about learning with cooperative techniques we include a table that summarizes the mean average points given to each statement and the standard deviation (Table 2). 
Table 1 Questionnaire on cooperative work (from 1 - not true for me, to 6 - totally true for me)

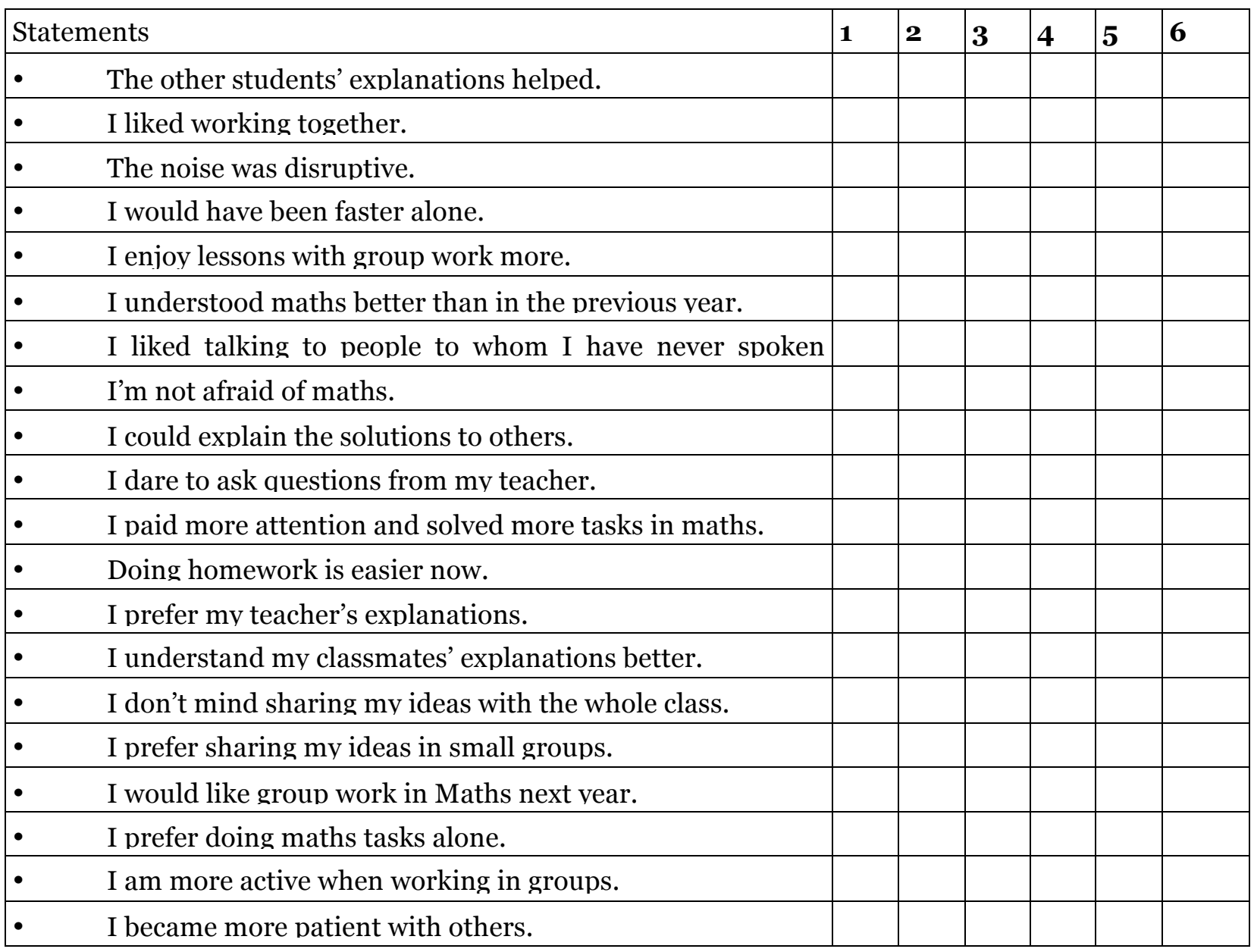

Table 2 Mean average and standard deviation of points given to each statement

\begin{tabular}{|l|l|l|l|l|l|l|l|l|l|l|l|l|l|l|l|l|l|l|l|l|}
\hline Statement & $\mathbf{1}$ & $\mathbf{2}$ & $\mathbf{3}$ & $\mathbf{4}$ & $\mathbf{5}$ & $\mathbf{6}$ & $\mathbf{7}$ & $\mathbf{8}$ & $\mathbf{9}$ & $\mathbf{1 0}$ & $\mathbf{1 1}$ & $\mathbf{1 2}$ & $\mathbf{1 3}$ & $\mathbf{1 4}$ & $\mathbf{1 5}$ & $\mathbf{1 6}$ & $\mathbf{1 7}$ & $\mathbf{1 8}$ & $\mathbf{1 9}$ & $\mathbf{2 0}$ \\
\hline Mean average & 3.8 & 4.3 & 3.6 & 3.3 & 5.3 & 3.6 & 2.7 & 3 & 4.1 & 3.9 & 3.4 & 3.9 & 5.1 & 2.8 & 3 & 4.1 & 4.5 & 3.4 & 3.5 & 3.2 \\
\hline $\begin{array}{l}\text { Standard } \\
\text { deviation }\end{array}$ & 1.3 & 1.5 & 1.8 & 1.6 & 1.4 & 1.1 & 1.3 & 1.4 & 1.1 & 1.6 & 1.6 & 1.8 & 0.8 & 0.8 & 1.4 & 1.4 & 1.7 & 1.6 & 1.5 & 1.7 \\
\hline
\end{tabular}

Furthermore, we chose some statements from the questionnaire and below we present the points given to these statements by individual students and also compare some statements. The lines indicate the mean average point given to each statement;

1. "I liked working together" and "I would have been faster alone" (Table 3)

2. "I prefer my teachers explanations" and "I understand my classmates' explanations better" (Table 4)

3. "I don't mind sharing my ideas with the whole class" and "I prefer sharing my ideas in small groups" (Table 5)

4. 4. "I prefer doing maths tasks alone" and "I am more active when working in groups" (Table 6)

5. "I prefer doing maths tasks alone" and "I am more active when working in groups" (Table 6) 
Table 3 Comparing statements 2 and 4

2. " I liked working together."

4. "I would have been faster alone."

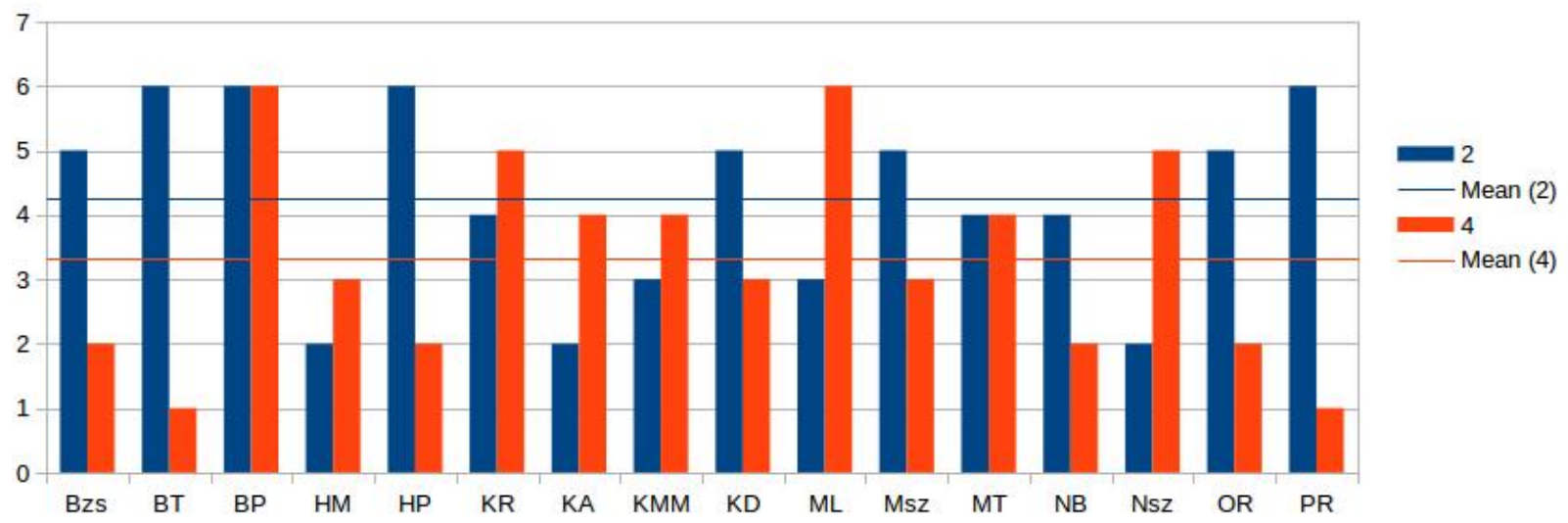

Table 4 Comparing statements 13 and 14

13. "I prefer my teacher’s explanations."

14. "I understand my classmates' explanations better."

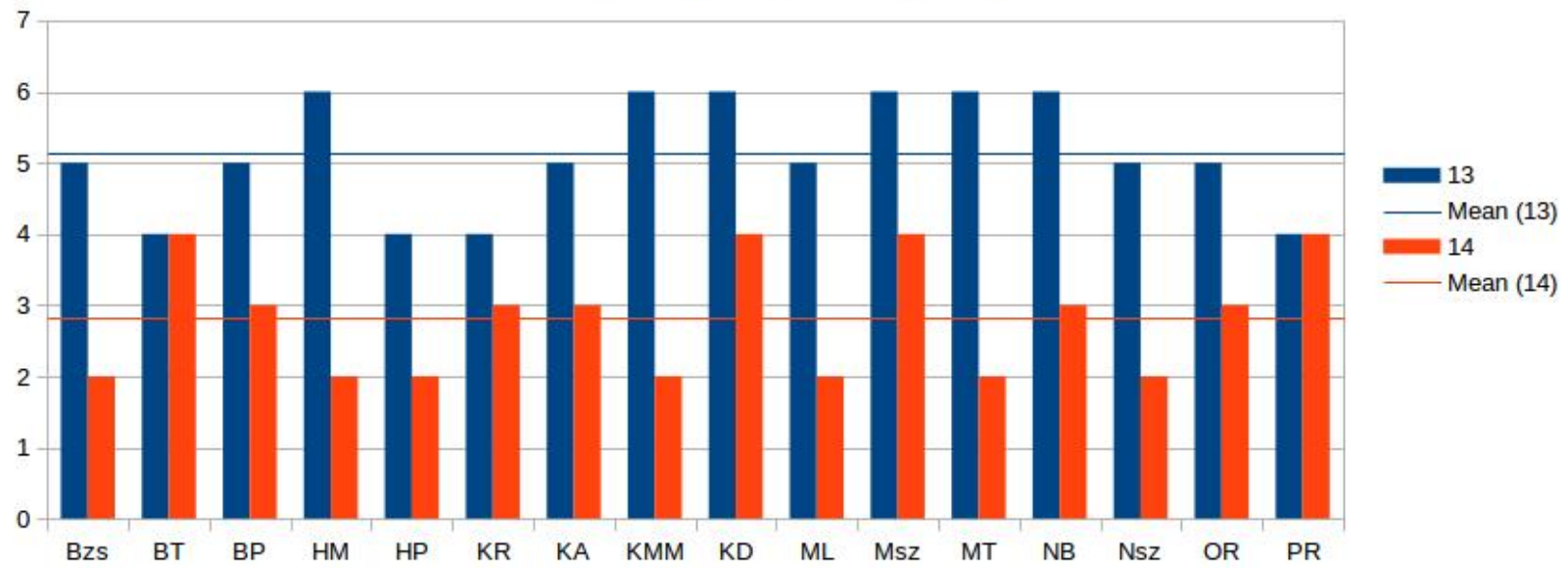

Table 5 Comparing statements 15 and 16

15. "I don't mind sharing my ideas with the whole class."

16. "I prefer sharing my ideas in small groups."

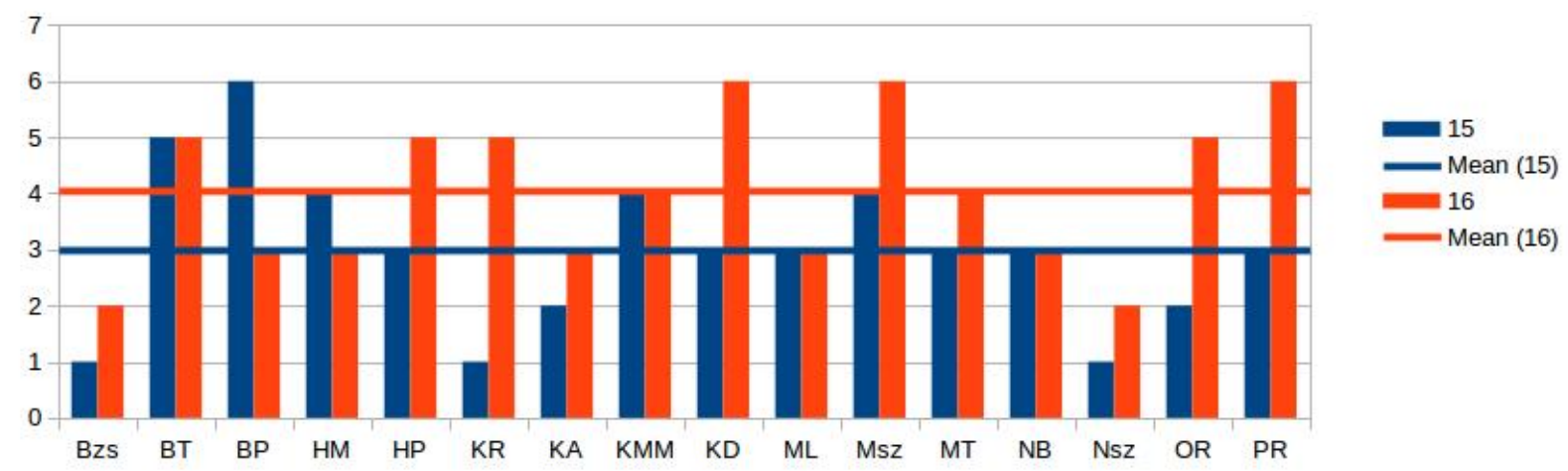


Table 6 Comparing statements 18 and 19

18. "I prefer doing maths tasks alone."

19. "I am more active when working in groups."

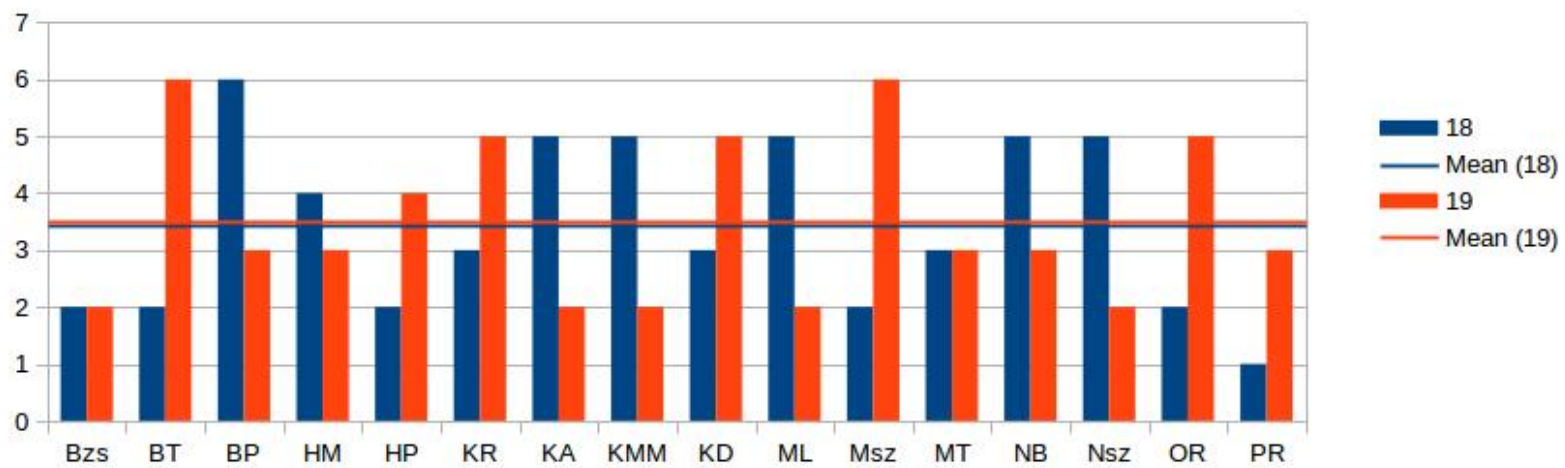

\subsection{The teacher's perspective}

In this section we present what happened in the two different types of lessons. The descriptions are based on the teacher's observation and notes made during the lesson.

\section{The frontal lesson}

The majority of the students worked really well on their own. Those who have a better understanding of mathematics used their previous knowledge confidently but some of the lower ability students often looked puzzled and they either tried to see what their neighbour was doing or they looked back in their exercise books to check previous examples that are similar to the task at hand. Some students asked the teacher's help when they got stuck, others had a short conversation with the person sitting next to them. When checking the solutions together only a few students participated in the discussion. Those who only listened checked their answers and copied the missing ones but never asked why a solution they wrote was incorrect or how to obtain the right answer.

\section{The cooperative lesson}

By the time this cooperative lesson was held the students had taken part in many lessons planned with cooperative techniques so they were used to working together (Figure 4).

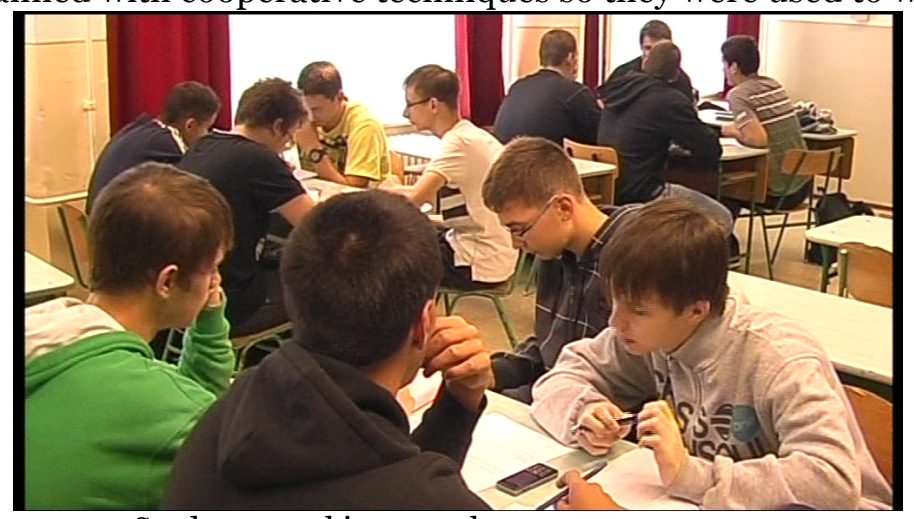

Figure 4 Students working together 
Of course each student had a different reaction to working in groups which - among many other factors - depended on their mathematical ability. The "good" ones often preferred working alone but they were confident when they had to share their thoughts with the other members of the group. For the less able student gathering ideas alone was not always easy. They often just waited for the other's explanations. But if they had ideas for the solution they were willing to share them. After a while they did not mind making mistakes or saying something that is incorrect.

\section{Conclusion}

Based on the above-mentioned observations it can be stated that both using cooperative techniques and presenting an open problem to the students had advantages and disadvantages.

\section{Cooperative techniques}

Cooperation allowed students to work in their own pace, slower students had time to understand the task better while faster ones could be given a so called time filler activity in the above mentioned example they had to justify why certain triangles are possible or not. Moreover, working in groups facilitated communication among students and encouraged them to use mathematical language when explaining ideas to each other, furthermore it inspired even the less able students to participate more actively in the problem solving process. (Barczi, 2014) This working format contributed to a kind of personal development of the students as well. Many of them became more patient with their classmates and more tolerant. As for the teacher, she had a better opportunity to help students individually and had a better insight into the students' way of thinking and methods of problem solving.

However, applying cooperative techniques is definitely time-consuming. In class fewer problems could be discussed. This working format is noisy which is disruptive for some students (see the questionnaire above) and individual personalities should be taken into consideration too as some students perform better when working alone. Planning a cooperative lesson requires more preparation and more creativity from the teacher and when teaching such a lesson she/he must be in full control of the class because it is the teacher's responsibility to maintain an atmosphere that in spite of being noisy is suitable for efficient work.

All in all, cooperative techniques can be considered as an effective tool for developing problem solving skills but they should be used alongside and mixed with other methods.

\section{Open problems}

The investigation task - and the rest of the open problems used in the experiment - gave the opportunity for the less able students to get started with concrete values or with visual representations. In case of the problems presented above they could starts drawing some triangles and labelling the sides and angles then checking with calculations whether they 
can be existing triangles or not. However, they needed the teacher's assistance in listing all options in a logical order and justifying why a concrete arrangement is a triangle or not.

In case of an investigation more solution can occur or the same solution can be found in different ways. Checking each student's solutions and discussing everyone's idea in class takes a lot of time and is difficult to manage. For tackling open problems and investigations cooperative techniques were useful as the discussion of many ideas was much easier in small groups.

On the whole, open problems and investigations also contributed well to developing problem solving skills and although they were time-consuming, combined with cooperative teaching techniques they provided an opportunity for discussing fewer problems but in greater detail. As mentioned in the introduction we were looking for methods with which we can reach not only the top $10-15 \%$ of our students and we can involve the average student in active learning. Cooperative techniques and open problems were efficient tools.

\section{Working memory, cognitive load}

As mentioned previously working memory plays a vital role in problem solving. First, it has an important part in understanding the task. When using cooperative work students could discuss the original question with each other and they had the opportunity to clarify what needs to be done. Second, when looking for a solution method they could rely not only on their knowledge but on the knowledge of the other members of the group. Third, in checking progress and noticing occasional mistakes the students could help each other. All the above mentioned factors contributed to the extension of the working memory of the participants. One of the students wrote that working together was more effective then working alone as there was always someone who had an idea or knew how to proceed. The student said that their knowledge was put together this way. As for the cognitive load, when working in groups there were less elements to process simultaneously since the work was shared between the members of the groups. It was the task of more students to remember facts and figures related to the problem and the groups contained students with mixed mathematical abilities and experience in problem solving. So their cognitive load was reduced.

\section{Future plans}

Based on the qualitative data collected during the experiment and on personal experience in the future cooperative teaching techniques will be used in my mathematics lessons; open problems and investigations are also good tools for enriching our mathematical education, so another plan is to "open" some often-used Hungarian problems and present them in this form to our students. When carrying out an educational experiment it is also important that other teachers find out about the results, so spreading the ideas and the results of the experiment is among the future tasks, too. 


\section{References}

Ambrus, A. (2004). Bevezetés a matematika didaktikába (Introduction to Mathematical Didactics). Budapest: ELTE Eötvös kiadó.

Ambrus, A. (2014). Teaching Mathematical Problem-Solving with the Brain in Mind. CEPS Journal, Slovenia, 105-120.

Ayres, P., Kalygula, S., \& Sweller J. (2011). Cognitive Load Theory. Springer

Baddeley, A., Eysenk M. V., \& Anderson M. C. (2009). Memory. New York, NY: Psychology Press.

Barczi, K. (2014). How do they solve problems? Mathematical problem solving of the average and the talented. In A. Ambrus, \& É. Vásárhelyi. Problem Solving in Mathematics Education, proceedings from the $15^{\text {th }}$ ProMath conference, September 2013 (pp. 18-34). Eger: EKF.

Burns, M., (1990). Using Groups of four. In N. Davidson (Ed.), Cooperative learning in Mathematics (pp. 21 - 46). Boston, MA: Addison-Wesley Publishing Company.

Clark, R., Kirschner, P. A., \& Sweller. J. (2012). Putting Students on the Path to Learning. The Case for Fully Guided Instruction. American Educator, Spring, 6-11.

Dees, M., (1990). Coopeartion in the Mathematics Classroom: A User's Manual. In N. Davidson (Ed.), Cooperative learning in Mathematics (pp. 21 - 46). Boston, MA: Addison-Wesley Publishing Company.

Hattie, J., Yates, G. (2014). Visible Learning and the Science of How We Learn. London: Routledge.

Johnson, R. T. and Johnson, D. W. (1994). An Overview of Cooperative Learning. In J. Thousand., A. Villa and A. Nevin (Eds.), Creativity and Collaborative Learning. Baltimore, PA: Brookes Press.

Józsa, K. \& Székely, G. (2004). Kísérlet a kooperatív tanulás alkalmazására a matematika tanítása során (Experiment for Using Cooperative Learning in Teaching Mathematics). Magyar pedagógia, 104(3), 339-362.

Kagan, S. (2001). Kooperatív tanulás (Cooperative Learning). Budapest: Önkonet.

Kagan, S. (2003). A Brief History of Kagan Structures. Kagan Online Magazine. San Clemente, CA: Kagan Publishing.

Kagan, S. (2004). Kooperatív tanulás (Cooperative Learning) Budapest: Önkonet.

Koshy, V. (2005). Action Research for Improving Practice. London: Paul Chapman Publishing.

Mécs, A. (2009). Miben segíti a kooperatív módszer a matematika tananyag megértését? (How do cooperative teachniques help understand Mathematics?). (MSc dissertation). Budapest: ELTE.

Pehkonen, E. (1999). Open-ended Problems: A Method for an Educational Change. In International Symposium on Elementary Maths Teaching (SEMT 99). Prague: Charles University

Pólya, Gy. (1973). How to Solve it. New Jersey, NJ: Princeton University Press.

Slavin, R. E. (1995). Cooperative Learning. Boston, MA: Allyn \& Bacon.

Sweller, J. (1994). Cognitive Load Theory, Learning Difficulty and Instructional Design. Learning and Instruction, 4, 295-312

Tóth, L. (2007). Pszichológiai vizsgálati módszerek a tanulók megismeréséhez (Psychological methods for getting to know the students). Debrecen: Pedellus.

Way, J. (2013). Problem Solving: Opening up Problems. Retrieved: October, 21, 2013, from: http://nrich.maths.org/2471

Zimmermann, B. (1986). From Problem Solving to Problem Finding in Mathematics Education. In P. Kupari (Ed.), Mathematics Education Research in Finland, Yearbook 1985 (pp. 81-103 ). Jyväskylä: Institute for Educational Research.

Zimmermann, B. (2009). “Open ended Problem Solving in Mathematics Instruction and some Perspectives on Research Questions” revisited - New Bricks from the Wall? In A. Ambrus, \& É. Vásárhelyi. Problem Solving in Mathematics Education, proceedings from the $11^{\text {th }}$ ProMath conference, September 2009 (pp. 143-157). Budapest: ELTE. 